This is the post print version of the article, which has been published in Multiple Sclerosis and Related Disorders. 2018, 19, p. 109-114.

https://doi.org/10.1016/j.msard.2017.10.019

\title{
Common comorbidities and survival in MS: Risk for stroke, type 1 diabetes and infections
}

Annukka Murtonen, $\mathrm{MD}^{1}$, Samu Kurki, $\mathrm{PhD}^{2}$, Katariina Hänninen, $\mathrm{BM}^{3}$, Merja SoiluHänninen, $\mathrm{MD}^{3}, \mathrm{PhD}$, Marja-Liisa Sumelahti, $\mathrm{MD}, \mathrm{PhD}^{1}$

${ }^{1}$ University of Tampere, 33014- TaY, Finland and Tampere University Hospital, Department of Neurology, PL 2000,33521 Tampere, Finland.

Murtonen.Annukka.S@student.uta.fi

${ }^{2}$ Auria Biobank, University of Turku and Turku University Hospital, PL 52, 20521 Turku, Finland.

Samu.Kurki@tyks.fi

${ }^{3}$ Turku University Hospital, Division of Clinical Neurosciences and University of Turku, PL

52,20521

Turku, Finland

Katariina.Hanninen@utu.fi

Merja.Soilu-Hanninen@tyks.fi

Address for correspondence:

Marja-Liisa Sumelahti

e-mail: Marja-Liisa.Sumelahti@uta.fi.

Postal address: Arvo, 33014 SF-University of Tampere.

Tel. +358405874149

Authors have nothing to disclose

Key words: Multiple Sclerosis; Survival; Comorbidity; Circulatory diseases; Type 1 diabetes; Infections 


\section{Introduction}

Multiple sclerosis (MS) is a progressive autoimmune disease causing disability and premature mortality. Pathologically MS is characterized by inflammation, demyelination and neurodegeneration in the central nervous system (CNS). (1) Other mechanisms in CNS include changes in vascular perfusion, activation of microglia and intracerebral vascular changes like blood-brain barrier leakage. $(2,3)$

Autoimmune disorders, infections and circulatory diseases are common in MS population. $(4,5,6)$ Several disorders in these disease groups affect brain and the nervous system in MS, such as cardio- and cerebrovascular diseases, hypertension and diabetes. (7)

There is a risk for premature mortality in MS $(8,9)$ and the major cause of death are infections. It is increasingly recognized that the common causes of death observed in general population are present also in MS, such as cardiovascular causes and stroke (8-11). At the same time findings regarding the prevalence of several vascular comorbidities in MS are conflicting (12). An almost two-fold increased risk for cerebrovascular comorbidity and a significant risk for cardiovascular comorbidity after MS onset has been recently reported (13). This observation has raised a question of converging causal pathways of the coexisting diseases and a need to study the effects in a broader spectrum of comorbidities in MS. Vascular aspects in MS are thus recognized and the reported risk may be explained on basis of the inflammatory and vascular mechanisms present in both MS and circulatory diseases, in addition to suspected effect of shared genetic and life-style risk factors. $(14,15)$

Our study bases on these observations and hypotheses. We studied the age- and gender adjusted risk for circulatory diseases in an MS population diagnosed and followed-up in a large university hospital district in Southwest Finland. We focused on ischemic cerebro- and cardiovascular diseases and related disorders, diabetes and acute and chronic infections. An established public health care system and population registers in Finland form a reliable basis in our survey. By access to administrative and patient specific data from the Hospital District of Southwest Finland we studied the coincident risk and survival effect for circulatory diseases 
and related comorbidities in MS, to assess the need of preventive actions and practical treatment strategies.

\section{Materials and methods}

This study was registered and approved by the Turku Clinical Research Center, Finland. Ethical committee approval was obtained from the joint Ethics Committee of the Tampere University and Pirkanmaa Hospital District, Finland.

For data mining, we used the administrative Clinical Data Repository of the University Hospital of Turku containing electronic health records at the Hospital District of Southwest Finland. These are collected directly and retrospectively monthly from the operational patient data systems from the central and university hospitals of the region by using ICD-10 codes (International Statistical Classification of Diseases and Related Health Problems 10th Revision (ICD-10)-WHO Version for 2016) from 1.1.2004 to 31.12.2012.

All resident cases with MS (ICD-10 code G35) were included. The catchment of data concerned both alive and deceased MS patients followed from 1.1.2004. Case ascertainment followed the initial data mining by scrutiny of each patient document by author K.H. to meet the study inclusion criteria of definite MS by McDonald criteria (16). Patient documents of the confirmed MS cases with diagnoses for cardiac (acute myocardial infarct I21), ischemic stroke (cerebral infarct, I62) and other vascular diseases of the brain were next scrutinized by the authors (M-L.S, A.M, M.S-H) for diagnostic ascertainment, including information on paraclinical diagnostics (date and results of brain CT or MRI scans, ECG and specific laboratory results). The ICD codes for causes of death among the deceased MS cases were collected from the patient records. Comorbidities diagnosed both before and after the date of diagnosis of definite MS were included in the analysis.

Confirmed MS cases in this nested case control study were gender- and age matched to controls drawn from the same population cohort. A 10-fold gender- and age (based on birth year) matched control population was randomly chosen from the CDR patient pool and another 
separate age- and gender-matched 10-fold control population was used to verify the stability of the results in the district.

All ICD-10 codes for each hospital visit were available for MS and control cases residing in the catchment area from 1.1.2004 to 31.12.2012. We collected data for ICD codes I06-I71 in Diseases of Circulatory Disease group, Chapter IX, I00-I71 and for other specific diagnoses under the study irrespective of time or age at each diagnosis. Dates of death were available from CDR.

\subsection{Statistical analyses}

Kaplan-Meier (KM) survival analysis was applied to study the mean survival times. A separate $\mathrm{KM}$ analysis was performed to study the effect of CD morbidity (I00-I71 codes). Significance was assessed by log-rank test.

The odds ratios, OR's, were calculated with $95 \%$ confidence intervals (95\% CI) and p-values were calculated using Pearson's $\chi^{2}$ test. All statistical tests were two-tailed and p-values less than 0.05 were considered statistically significant. Statistical analyses were performed using $\mathrm{R}$ Statistics version 3.0.2 with standard packages.

\section{Results}

A total of 1074 confirmed MS cases, 315 men and 759 women, were identified in a population of 472 139. The distribution of prevalent cases in 2004 and new incident cases from 2004 to 2012 by sex and age at entry is shown in Table 1. The date of entry is the first hospital visit due to any cause. 
During the follow-up death in MS occurred in 5.9\% (n 70, 34 women and 36 men). The main cause of death was infections (n 38,54.3\%). Other specific causes in the circulatory diseases group (n $5,7.1 \%$ ) were one case of acute myocardial infarct, four cases of ischemic stroke and one case of subarachnoid haemorrhage. Causes in other disease groups were respiratory insufficiency (n 6, 8.6\%), cancer (n 3, 4.3\%) and intoxication (n 2, 2.9\%). The rest of the death causes represented other causes of death (n 16, 22.9\%).

The mean survival time in MS was 82.4 years compared to 85.6 years in the age and gender matched control population, difference was statistically significant (KM log rank p <0.001), KM curve shown in Figure 1.

The MS prevalence in 31.12.2012 was 212.6 / 105 (95\% CI 199.5-225.8), 121.4 (114.5-128.4) for men and 258.3 (247.9-268.6) for women (17).

The diagnosed concomitant circulatory system diseases in ICD I06-I71 at any point of disease trajectory including death during the follow-up in 2004-2012 were included in the second KM analysis shown in Figure 2. The risk related to circulatory disease diagnoses in MS was statistically significant, log rank $\mathrm{p}<0.001$ : the mean survival time among MS cases with circulatory diseases was 79.5 years and without circulatory diseases 85.4 years. Survival among controls was 85.6 years. The odds ratios (OR) concerning MS and control cases in specific circulatory diseases ICD- groups I06-I71 (n=340) are shown in the additional data.

The number of MS, age- and gender matched control cases and OR's for specific circulatory diseases diagnoses are presented in Table 2. An almost 50\% greater risk for ischemic cerebral infarct in MS (n 25), OR 1.49 (95\% CI 1.03-2.35), was statistically significant. A statistically significant and over two-fold risk was observed also for other strokes (n 9) including both subarachnoid and intracerebral haemorrhages: OR 2.5 (1.24-5.06). Acute myocardial infarct (n $18,1.85 \%)$ showed no increased risk in MS, OR was 1.49 (0.91-2.43). Diagnoses with other 
cerebrovascular diseases by code I67 (n 9) and sequelae of cerebrovascular disease I69 (n 18) may overlap the acute stroke diagnoses why they were assessed separately. Respective OR's were high, 2.5 (1.24-5.06) and 1.73 (1.06-2.83).

Ischemic stroke (cerebral infarct, I63) was confirmed either as a comorbid diagnosis (n 21) or an immediate cause of death ( $\mathrm{n}$ 4). Case ascertainment was based on findings in CT scan or MRI in 92\% (23/25 cases), location was mainly parietal in middle artery region (n 11), posterior (n 6) and subcortical (n 6). Female to male ratio was 0.79 (11/13 cases). Mean age at cerebral infarct was 69.5 years, median 69 years (SD 10.58), 71.6/71 years (SD 9.93) for women and 67.86/67.5 years (SD 11.15) for men $\left(\chi^{2} \mathrm{p}=0.23\right.$, statistically nonsignificant). All cases in I67 (subarachnoid and intracerebral haemorrhage) were radiologically confirmed. Diagnosis of acute myocardial infarct diagnesis based on ECG and blood tests.

The number of MS, age- and gender matched control cases and OR's for common circulatory disease related risk factors are presented in Table 3. Type 1 diabetes showed a two-fold risk, OR 2.1 (1.3-3.36). A statistically nonsignificant risk was observed for type 2 diabetes, transient ischemic attack (TIA), atrial fibrillation, other cardiac arrhythmia, hypertension, hyperlipidaemia and obesity in MS.

The number of MS, age- and gender matched control cases and OR's for a number of acute and chronic infections are presented in Table 4. with detailed results. The coincident risk for the hospital treated infections showed an increased risk for urinary, respiratory and periodontal infections in MS.

\section{Discussion}

The lower mean survival time of 82.4 years in MS compared to 85.6 years in the control population was statistically significant. However, life expectancy was reduced much less than in earlier studies showing 6-7 years shorter life expectancy in MS $(8,9,18)$. This supports improved survival in patient cohorts from the era of disease modifying therapies and is in line with the 
recent study from Norway showing a near normal standardised mortality ratio in the patient cohort monitored from 1997 to 2012 (18).

The high mortality of cerebrovascular diseases in the Finnish general population (19) was here shown to concern also the MS population. Result supports the Danish study (5) and corroborates survival disadvantage reported for cerebrovascular diseases among MS patients. (10-13) Survival disadvantage related to circulatory disease comorbidity was significant in our study. The mean survival time was lower for MS cases with any circulatory diseases related diagnosis in ICD-10 I06-I71 group, 79.5 years, in comparison with the 85.4 years in MS patients without it. The specific risk for the common risk factors for these diseases, such as hypertension, hyperlipidaemia or cardiac disorders and arrhythmias, were low also in our MS population (20) along with other risk factors for ischemic stroke, except for type 1 diabetes.

MS patients were followed up during a 9-year period in 2004-2012. The catchment area in the Hospital District of Southwest Finland represents a high-risk region of MS, where prevalence was $212 / 10^{5}$ in 2012. (17) MS cohort originated from an administrative database and after confirmation of MS diagnosis $9.6 \%$ of cases were excluded, which amount is similar to other reports using administrative catchment. $(5,20)$ Patient records were examined for confirmation of MS, ischemic brain and myocardial infarcts and for causes of death, why we believe to have reliable data for the statistical assessment concerning these diagnoses. The diagnosis of type 1 diabetes was considered reliable in this population due to regular hospital controls.

Strength of our study is the public health care system, where health care is available for all Finnish citizen and an equal treatment practice is followed. The national and hospital registers in Finland base on personalized identification code and are regarded reliable. The administrative health registry covers almost the entire population of the study region and provides objective data avoiding bias related to patient recall. MS is diagnosed and treated by neurologist in central and university hospitals why we believe to have a representative sample of MS patients from a large hospital district. A 10-fold sample of the general non-MS population ensure that study observations reflect general patterns of co-occurrence of health problems among MS patients, which may not be accurate in small clinical samples, due to sampling, or referral biases.

We observed an increased risk for circulatory diseases in MS population as compared to age- and sex matched control population during the follow-up. Evidence that autoimmunity may play an 
essential role in the pathogenesis of atherosclerosis (21) is supported by reports on increased risk for cerebro- and cardiovascular disorders in several immune-mediated diseases, such as MS (22), rheumatoid arthritis $(23,24)$ and type 1 diabetes (25). These results suggest that these inflammatory diseases may share pathological links with cerebrovascular diseases. However, although inflammation is shown to contribute to stroke risk (26), other typical risk factors may be absent in MS. $(25,27)$ This view was supported by observations in our data, as other common cerebrovascular risk factors, such as TIA, atrial fibrillation and other arrhythmias, showed no increased risk, nor was there any risk for secondary hypertension, hyperlipidaemia or obesity. Result differs from observations in rheumatoid arthritis and type 1 diabetes populations, where several common risk factors exist, but corroborates observations in other MS populations where prevalence of diabetes, hypertension, and hyperlipidaemia have been similar to rates in general population. (20)

Given the observation of increased risk for stroke, which is diagnosed in hospital, and the low comorbidity for some of the most common vascular disease risk factors, our results are discordant but in accordance with other studies. (20) Limitation in our study population however concerns the catchment of these risk diagnoses from the tertiary care hospital data, as most of these conditions are recognized and treated mainly in the primary care. It also remains unknown to what content the observed circulatory disease risk is related to metabolic syndrome in MS, a question which has remained open also in other studies addressing this relation and the increased risk of obesity or changes in body composition, hypertension, dyslipidaemia or type II diabetes in MS (27). Although administrative data are considered a valid means of tracking diabetes, hypertension, and hyperlipidaemia in MS (27) the so far inconclusive results from hospital data regarding common circulatory disease risk factors in MS as shown here could be elaborated by linkage to other databases and primary care data.

Respiratory infections were the major cause of death and the high rates of acute and chronic respiratory, urinary and periodontal infections were present also in our MS cohort. $(8,11,28)$ Acute and chronic infectious diseases are related to risk of stroke (29) and infections may be a specific risk factor in MS population. There is a connection between the immunological and vascular factors (30), which supports the suggested hypothesis on the shared inflammatory mechanisms in MS and ischemic stroke (31). The control of inflammation and infections appear as important modifiable factors in MS related circulatory disease risk. Evidence from observational studies shows that vaccination against influenza is associated with a reduced risk 
of stroke, myocardial infarction and all-cause mortality. (32) The preventive seasonal and H1N1 vaccines are safe and efficacious also among MS patients, nor is there any reduced response to vaccination against influenza associated to majority of immunomodulatory drugs used in MS. (33)

The independent coincident relative risk for type 1 diabetes in our MS population was high and corroborates results in other studies (34). In Finland, the incidence of both type 1 diabetes and MS are high (35). The autoimmune pathogenesis of MS and type 1 diabetes (6) as well as socioeconomic, environmental and latitude correlated factors may contribute to the predisposition of these immune-mediated diseases. The global and steep increase in both type 1 and 2 diabetes (36) and MS incidences recorded in the last half of the 1990's may be a serious signal of unhealthy changes in the environment and life style. These may affect the penetrance of disease susceptibility genes in autoimmune diseases and may also be involved in the high circulatory disease risk observed in MS and type 1 diabetes in Finland. The modifiable risk factors in type 1 diabetes, MS and circulatory diseases include childhood obesity and smoking.

MS patients today expect a longer survival. The long disease trajectory combines an increased risk for comorbidities common in the general population, as shown here for ischemic stroke risk along with other studies. Consistent with other reports, limitation for information regarding circulatory disease mortality related life-style factors here concerns the lack of socioeconomic and lifestyle information in MS cohorts. At the moment, we have no information on the changes in occupational status, medication, weight, serum lipid status or on individual lifestyle factors such as smoking, dietary habits, physical activity or health behaviour in general, but evidence on accumulating comorbidity risk in MS supports the importance of dealing with these factors. Life style interventions are justifiable as the key findings in comorbidity studies in MS have been association of life-style related type 2 diabetes, hypertension, dyslipidaemia or peripheral vascular disease at any point in the disease course with a greater progression in disability. (20) These factors may add to complex risk for circulatory diseases in MS and have implications for prevention and treatment in the recognized risk groups. Disadvantages in administrative databases such as ours include the lack of structured data on life style factors. We expect to expand the information in our databases in the future with the application of text mining tools to patient reports and linkage to other governmental health registries such as the medication reimbursement registry of social insurance institution of Finland. 
The immortal time bias is a limitation for inferences in cohort and case-control study designs, however a nested case-control analysis as chosen here, and matching by age and sex, may be much less susceptible to selection bias than the other approaches since controls are known to represent the source population that gave rise to the cases and the analysis can include all the cases from the source population. (38) This analytical technique has not only been shown to provide an unbiased estimate of the hazard ratio that would be obtained from a traditional time to event analysis of the full cohort $(39,40,41)$ and its inherent time dependent nature means that it is also free of immortal time bias.

In conclusion, the overall survival advantage in MS was related to lack of circulatory disease diagnoses at any point during the follow-up. Further knowledge on influences of comorbidities on the course and outcome of MS is important for better clinical care and optimized life style interventions in the individual patients.

5. References:

1. Hauser SL, Goodwin DS. Multiple sclerosis and other demyelinating diseases. In: Fauci AS, Braunwald E, Kasper DL, Hauser SL, editors. Harrison's principles of internal medicine. 17th ed. II. ed. New York: McGraw-Hill Medical; 2008. p. 2611-2621.

2. Cramer SP, Simonsen H, Frederiksen JL, Rostrup E, Larsson HBW. Abnormal bloodbrain barrier permeability in normal appearing white matter in multiple sclerosis investigated by MRI. Neuroimage Clin. 2013;10:182-9.

3. Wuerfel J, Paul F, Zipp F. Cerebral blood perfusion changes in multiple sclerosis. J Neurol Sci. 2007;259:16-20.

4. Montgomery S, Hillert J, Bahmanyar S. Hospital admission due to infections in multiple sclerosis patients. Eur J Neurol. 2013;20:1153-60.

5. Christiansen CF, Christensen S, Farkas DK, Miret M, Sorensen HT, Pedersen L. Risk of arterial cardiovascular diseases in patients with multiple sclerosis: A population-based cohort study. Neuroepidemiology. 2010;35:267-74.

6. Berkovich R, Subhani D, Steinman L. Autoimmune comorbid conditions in multiple sclerosis. US Neurol. 2011;7:132-8. 
7. Marrie RA, Cohen J, Stuve OA et a. Asystematic review of the incidence and prevalence of comorbidity in multiple sclerosis: overview. Mult Scler. 2015 Mar;21(3):263-81. doi: 10.1177/1352458514564491. Epub 2015 Jan 26.

8. Sumelahti ML, Hakama M, Elovaara I, Pukkala E. Causes of death among patients with multiple sclerosis. Mult Scler. 2010;16:1437-42.

9. Kingwell E, van der Kop MF, Zhao YF, et al. Relative mortality and survival in multiple sclerosis: findings from British Columbia, Canada. J Neurol Neurosurg Psychiatry. 2012;83:61-6.

10. Krökki O, Bloigu R, Ansakorpi H, Reunanen M, Remes AM. Neurological comorbidity and survival in multiple sclerosis. Mult Scler Relat Disord. 2014;3:72-7.

11. Bronnum-Hansen H, Koch-Henriksen N, Stenager E. Trends in survival and cause of death in Danish patients with multiple sclerosis. Brain. 2004;127:844-50.

12. Marrie RA, Reider N, Cohen J et al. A systematic review of the incidence and prevalence of cardiac, cerebrovascular, and peripheral vascular disease in multiple sclerosis. Mult Scler. 2015 Mar;21(3):318-31. doi: 10.1177/1352458514564485. Epub 2014 Dec 22.

13. Thormann A, Magyari M ,Koch-Henriksen N, Laursen B, Sørensen PS.Vascular comorbidities in multiple sclerosis: a nationwide study from Denmark. J Neurol. 2016 Dec;263(12):2484-2493. Epub 2016 Oct 3.

14. D'haeseleer M, Cambron M, Vanopdenbosch L, De Keyser J. Vascular aspects of multiple sclerosis. Lancet Neurol. 2011;10:657-66.

15. Wang Y, Bos SD, Harbo HF, Thompson WK, Schork AJ, Bettella F, et al. Genetic overlap between multiple sclerosis and several cardiovascular disease risk factors. Mult Scler. 2016;22:1783-93.

16. Polman C, Reingold S, Banwell B, Clanet M, Cohen JA, Filippi M, et al. Diagnostic criteria for multiple sclerosis: 2010 revisions to the McDonald criteria. Ann Neurol. 2011;69:292-302.

17. Åivo J, Kurki S, Sumelahti M-, Hänninen K, Ruutiainen J, Soilu-Hänninen M. Risk of osteoporotic fractures in multiple sclerosis patients in southwest Finland. Acta Neurol Scand. 2016:ePub ahead of print 22 Jun.

18. Lunde HMB, Assmus J, Myhr KM et al. Survival and cause of death in multiple sclerosis: a 60-year longitudinal population study. J Neurol Neurosurg Psychiatry. 2017 Apr 1. pii: jnnp-2016-315238. doi: 10.1136/jnnp-2016-315238. [Epub ahead of print] 
19. Causes of death, Statistics Finland. http://www.stat.fi/til/ksyyt/2012/ksyyt_2012_2013$\underline{12-30 \text { tie } 001 \text { en.html. }}$

20. Marrie RA, Yu BN, Leung $\mathrm{S}$ et al. Rising prevalence of vascular comorbidities in multiple sclerosis: Validation of administrative definitions for diabetes, hypertension, and hyperlipidemia. Mult Scler. 2012;18:1310-19.

21. Matsuura E, Atzeni F, Sarzi-Puttini $P$ et al. Is atherosclerosis an autoimmune disease? BMC Med. 2014;12:47.

22. Capkun G, Dahlke F, Lahoz R et al. Mortality and comorbidities in patients with multiple sclerosis compared with a population without multiple sclerosis: An observational study using the US department of defense administrative claims database. Mult Scler Relat Disord. 2015;4:546-54.

23. Nurmohamed MT, Heslinga M, Kitas GD. Cardiovascular comorbidity in rheumatic diseases. Nat Rev Rheumatol. 2015 Dec;11(12):693-704.

24. Meissner Y, Richter A, Manger B et al.Serious adverse events and the risk of stroke in patients with rheumatoid arthritis: results from the German RABBIT cohort. Ann Rheum Dis. 2017 May 8. pii: annrheumdis-2017-211209. doi: 10.1136/annrheumdis-2017211209.

25. O'Donnell MJ, Chin SL, Rangarajan S et al., INTERSTROKE investigators.Global and regional effects of potentially modifiable risk factors associated with acute stroke in 32 countries (INTERSTROKE): a case-control study. Lancet. 2016 Aug 20;388(10046):761-75. doi: 10.1016/S0140-6736(16)30506-2. Epub 2016 Jul 16.

26. Dregan A, Chowienczyk P, Molokhia M. Cardiovascular and type 2 diabetes morbidity and all-cause mortality among diverse chronic inflammatory disorders. Heart. 2017 Jun 10. pii: heartjnl-2017-311214. doi: 10.1136/heartjnl-2017-311214. [Epub ahead of print]

27. Wens I, Dalgas U, Stenager E, Eijnde BO. Risk factors related to cardiovascular diseases and the metabolic syndrome in multiple sclerosis - a systematic review. Mult Scler. 2013;19:1556-64.

28. Sheu J, Lin H. Association between multiple sclerosis and chronic periodontitis: A population-based pilot study. Eur J Neurol. 2013;20:1053-59.

29. Lindsberg PJ, Grau AJ. Inflammation and infections as risk factors for ischemic stroke. Stroke. 2003:2518-32.) 
30. Caprio MG, Russo C, Giugliano A et al. Vascular Disease in Patients with Multiple Sclerosis: A Review. Vasc Med Surg 2016, 4:2 http://dx.doi.org/10.4172/23296925.1000259

31. Claudio L, Fau RC, Brosnan CF. Evidence of persistent blood-brain barrier abnormalities in chronic-progressive multiple sclerosis. Acta Neuropathol. 1995;90:22838.

32. Urbanek C, Palm F, Grau AJ. Influenza and stroke risk: a key target not to be missed? Infect Disord Drug Targets. 2010 Apr;10(2):122-31.

33. Auriel E, Gadoth AF, Regev KF, Karni A. Seasonal and H1N1v influenza vaccines in MS: Safety and compliance. J Neurol Sci. 2012;314:102-3.

34. Fromont A, Binquet C, Rollot F, Despalins R, Well A, Clerc L, et al. Comorbidities at multiple sclerosis diagnosis. J Neurol. 2013;260:2629-37.

35. Karvonen M, Viik-Kajander M, Moltchanova E, Libman I, LaPorte R, Tuomilehto J. Incidence of childhood type 1 diabetes worldwide. diabetes mondiale (DiaMond) project group. Diabetes care. 2000;23:1516-26.

36. World Health Organisation. Global report on diabetes. Geneva. 2016.

37. Ponsonby AL, Lucas RM, Dear K, van der Mei I, Taylor B, Chapman C, et al. The physical anthropometry, lifestyle habits and blood pressure of people presenting with a first clinical demyelinating event compared to controls: The ausimmune study. Mult Scler. 2013;19:1717-25.

38. Lévesque LE, Hanley JA, Kezouh A, Suissa S. Problem of immortal time bias in cohort studies: example using statins for preventing progression of diabetes. BMJ. 2010;340:b5087.

39. Liddell FDK, McDonald JC, Thomas DC. Methods of cohort analysis: appraisal by application to asbestos mining. J R Stat Soc Ser A 1977;140:469-91.

40. Breslow NE, Day NE, eds. Fitting models to continuous data. Statistical methods in cancer research. Vol.2. The design and analysis of cohort studies. IARC Scientific Publications, 1987:178-229.

41. Suissa S. Novel approaches to pharmacoepidemiology study design and statistical analysis. In: Strom BL, ed. Pharmacoepidemiology. 4th ed. John Wiley, 2005:811-29. 


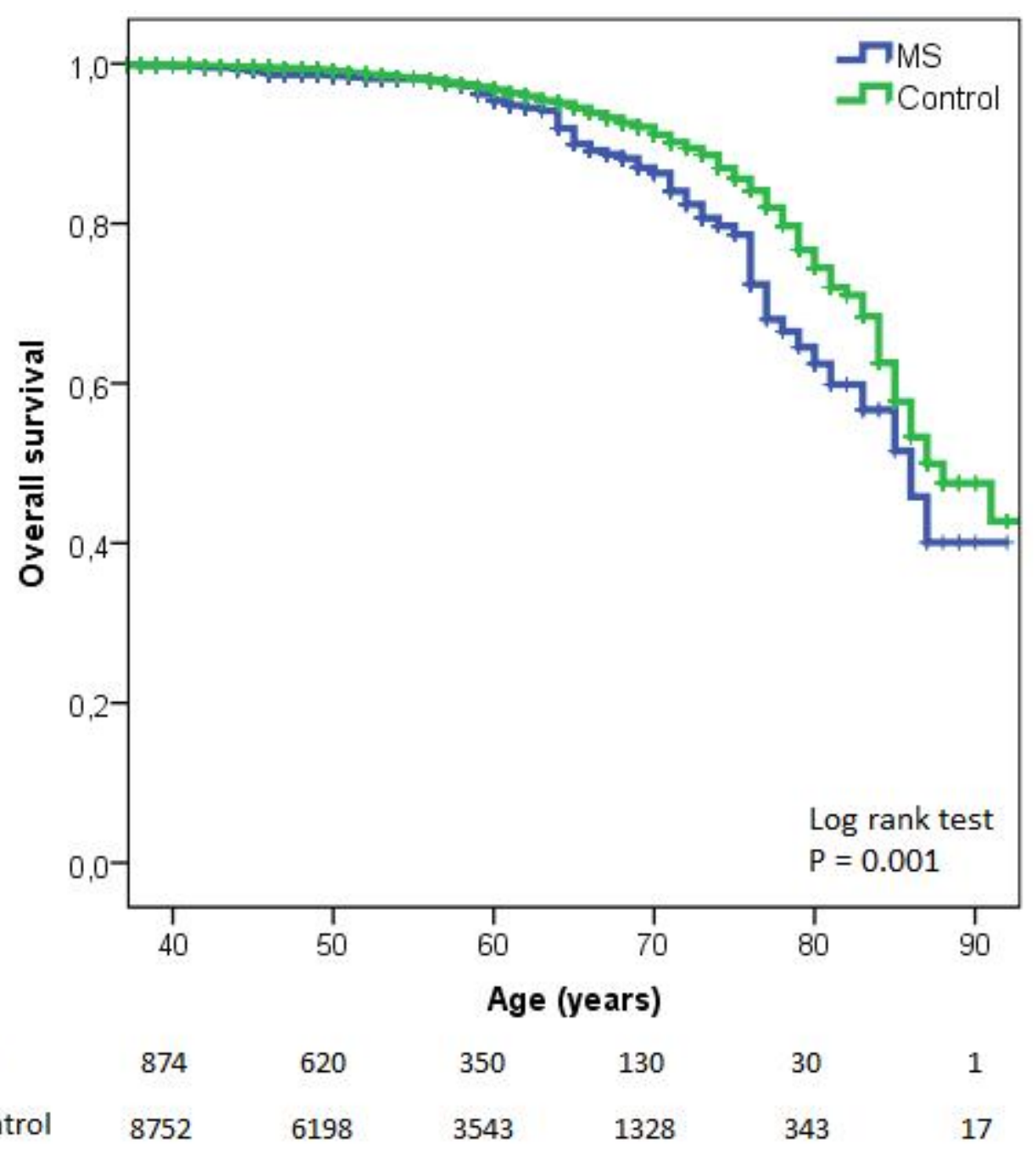

Figure 1. Kaplan-Meier survival curve from birth up to end of follow-up or at the point of death due to any cause for MS and age- and gender matched control cases. MS cases were enrolled from 1.1.2004 to 31.12.2012 in the Hospital District of Southwest Finland. The numbers below refer to the number of cases in each group that are still part of the follow-up at that time and have not experienced an event. 


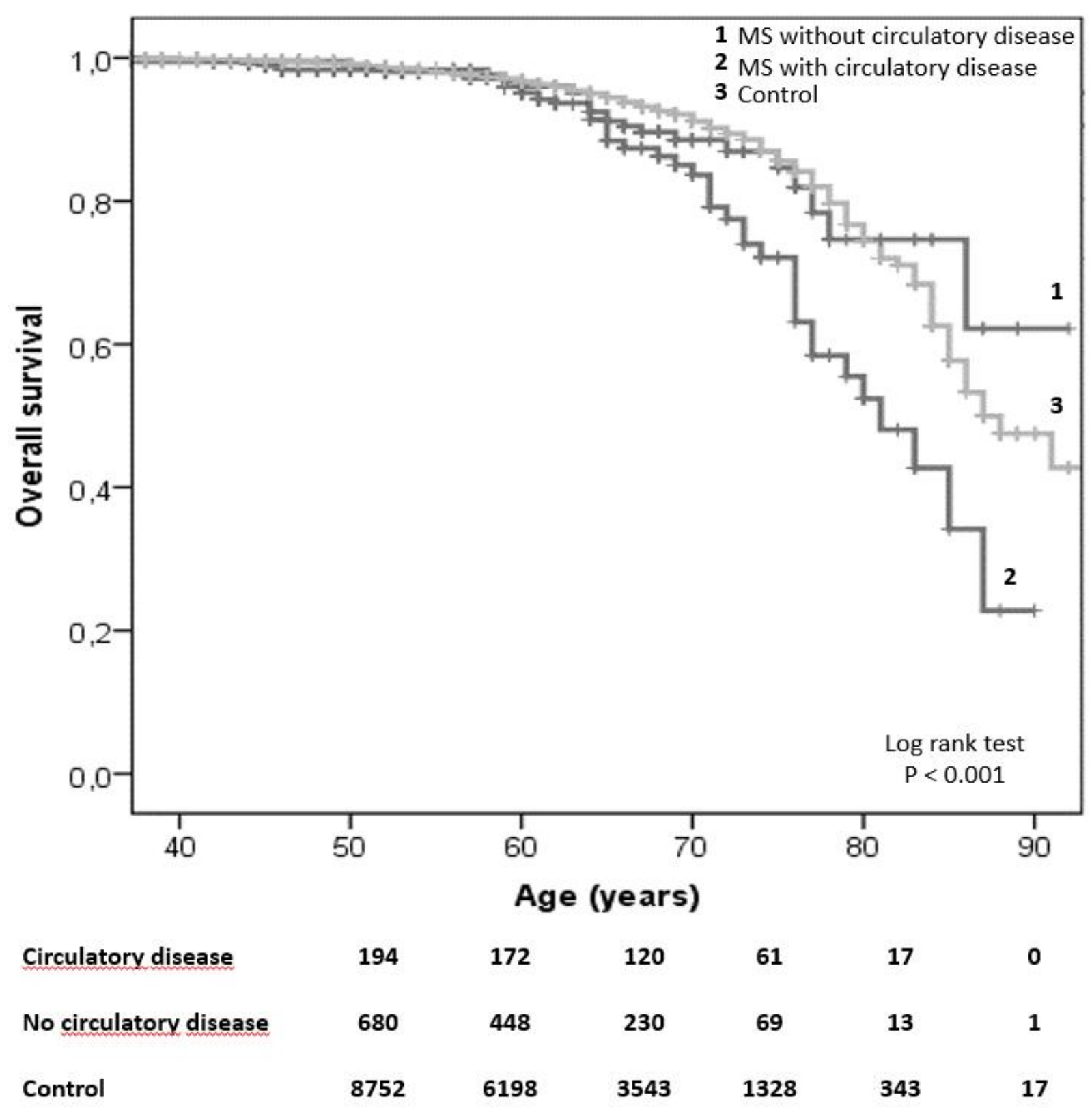

Figure 2. Kaplan-Meier survival curve for MS cases with and without circulatory disease diagnosis and for the age- and gender matched controls from birth up to end of follow-up or at the point of death due to any cause. Cases were enrolled from 1.1.2004 to 31.12.2012 in the Hospital District of Southwest Finland. The numbers below refer to the number of cases in each group that are still part of the follow-up at that time and have not experienced an event. 
Table 1. Number, mean age and standard deviation (years) at enrollment from 1.1.2004 to 31.12.2012 among the 1074 MS cases (ICD-10 G35) by gender in the Hospital District of Southwest Finland.

\begin{tabular}{|c|c|c|c|c|c|c|c|}
\hline \multicolumn{4}{|c|}{ Female } & \multicolumn{4}{|c|}{ Male } \\
\hline Year of entry & M ean age & Std dev & Number of cases & Year of entry & M ean age & Std dev & Number of cases \\
\hline 2004 & 44.6 & 12.0 & 212 & 2004 & 47.7 & 13.8 & 111 \\
\hline 2005 & 46.8 & 13.2 & 159 & 2005 & 50.3 & 14.1 & 53 \\
\hline 2006 & 44.4 & 12.7 & 79 & 2006 & 48.2 & 14.4 & 34 \\
\hline 2007 & 42.6 & 14.3 & 50 & 2007 & 49.2 & 14.5 & 26 \\
\hline 2008 & 45.4 & 15.7 & 61 & 2008 & 42.7 & 13.1 & 33 \\
\hline 2009 & 44.9 & 17.6 & 52 & 2009 & 45.1 & 13.9 & 18 \\
\hline 2010 & 48.7 & 14.2 & 49 & 2010 & 49.1 & 15.1 & 14 \\
\hline 2011 & 41.9 & 14.5 & 52 & 2011 & 45.9 & 15.1 & 16 \\
\hline 2012 & 45.9 & 18.5 & 45 & 2012 & 49.6 & 18.6 & 10 \\
\hline Total & 44.9 & 13.8 & 759 & Total & 47.5 & 14.1 & 315 \\
\hline
\end{tabular}

Table 2. The number, percentage and coincident odds ratio (OR) with $95 \%$ confidence interval (CI) for the diagnosed and confirmed cases in acute myocardial infarct, cerebral infarct and other vascular disease of the brain for MS cases compared to age- and gender matched control cases from 1.1.2004 to 31.12.2012 in the Hospital Distict of Southwest Finland.

\begin{tabular}{|c|c|c|c|c|c|c|c|}
\hline ICD-10 code & Disease & MS (n) & $\%$ & Controls (n) & $\%$ & OR & $95 \% \mathrm{CI}$ \\
\hline $\mathrm{I} 21$ & Acute myocardial infarct & 18 & 1.7 & 121 & 1.1 & 1.49 & $0.91-2.43$ \\
\hline I63 & Cerebral infarct & 25 & 2.3 & 161 & 1.5 & 1.55 & $1.03-2.35$ \\
\hline \multirow[t]{2}{*}{ I67 } & Other vascular disease & & & & & & \\
\hline & of the brain & 9 & 0.8 & 36 & 0.3 & 2.50 & $1.24-5.06$ \\
\hline
\end{tabular}


Table 3. The number, percentage and coincident odds ratio (OR) with $95 \%$ confidence interval (CI) for the common circulatory diseases diagnosed in hospitals for MS cases compared to ageand gender matched control cases from 1.1.2004 to 31.12.2012 in the Hospital Distict of Southwest Finland.

\begin{tabular}{|c|c|c|c|c|c|c|c|}
\hline $\begin{array}{l}\text { ICD-10 } \\
\text { code }\end{array}$ & Disease & MS & $\%$ & Controls & $\%$ & OR & $95 \% \mathrm{CI}$ \\
\hline G45 & TIA & 12 & 1.1 & 136 & 1.3 & 0.88 & $0.49-1.59$ \\
\hline $\mathrm{I} 48$ & $\begin{array}{l}\text { Atrial or fibrillation or } \\
\text { flutter }\end{array}$ & 18 & 1.7 & 350 & 3.3 & 0.51 & $0.33-0.81$ \\
\hline I49 & Other cardiac arrythmia & 18 & 1.7 & 189 & 1.8 & 0.95 & $0.59-1.54$ \\
\hline $\mathrm{I} 10$ & Essential hypertension & 93 & 8.7 & 1034 & 9.6 & 0.90 & $0.74-1.10$ \\
\hline $\mathrm{I} 70$ & Atherosclerosis & 12 & 1.1 & 102 & 1.0 & 1.18 & $0.65-2.13$ \\
\hline E10 & Type I diabetes mellitus & 20 & 1.9 & 95 & 0.9 & 2.11 & $1.32-3.36$ \\
\hline E11 & Type II diabetes mellitus & 39 & 3.6 & 391 & 3.6 & 1.00 & $0.72-1.38$ \\
\hline E78 & Hyperlipidemia & 17 & 1.2 & 336 & 3.1 & 0.51 & $0.32-0.81$ \\
\hline E66 & Obesity & 21 & 2.0 & 328 & 3.1 & 0.64 & $0.42-0.99$ \\
\hline
\end{tabular}


Table 4. The number, percentage and coincident odds ratio (OR) with $95 \%$ confidence interval (CI) for common acute and chronic infections diagnosed in hospital for MS cases compared to age- and gender matched control cases from 1.1.2004 to 31.12.2012 in the Hospital Distict of Southwest Finland.

\begin{tabular}{|c|c|c|c|c|c|c|c|}
\hline $\begin{array}{l}\text { ICD }-10 \\
\text { code }\end{array}$ & Disease & MS (n) & $\%$ & Controls (n) & $\%$ & OR & $95 \%$ CI \\
\hline N10 & Acute pyelonephritis & 88 & 8.2 & 116 & 1.1 & 7.59 & $6.01-9.57$ \\
\hline $\mathrm{J} 22$ & $\begin{array}{l}\text { Unspecified acute lower respiratory } \\
\text { infection }\end{array}$ & 7 & 0.7 & 10 & 0.1 & 7.0 & $3.06-16.03$ \\
\hline N30 & Cystitis & 81 & 7.5 & 116 & 1.1 & 6.98 & $5.48-8.89$ \\
\hline $\mathrm{J} 41$ & $\begin{array}{l}\text { Simple and mucopurulent chronic } \\
\text { bronchitis }\end{array}$ & 4 & 0.4 & 7 & 0.1 & 5.71 & $1.93-16.92$ \\
\hline A41 & Other sepsis & 29 & 2.7 & 62 & 0.6 & 4.68 & $3.14-6.97$ \\
\hline $\mathrm{J} 18$ & Pneumonia, unspecified organism & 100 & 9.3 & 297 & 2.8 & 3.37 & $2.73-4.15$ \\
\hline K02 & Dental caries & 25 & 2.3 & 90 & 0.8 & 2.78 & $1.82-4.24$ \\
\hline $\mathrm{J} 20$ & Acute bronchitis & 25 & 2.3 & 102 & 0.95 & 2.45 & $1.61-3.73$ \\
\hline K05 & Gingivitis and periodontal diseases & 23 & 2.1 & 101 & 0.94 & 2.28 & $1.47-3.53$ \\
\hline A04 & Other bacterial intestinal infections & 14 & 1.3 & 62 & 0.6 & 2.26 & $1.29-3.96$ \\
\hline K08 & $\begin{array}{l}\text { Other disorders of teeth and supporting } \\
\text { structures }\end{array}$ & 18 & 1.7 & 86 & 0.8 & 2.09 & $1.28-3.43$ \\
\hline L02 & Cutaneous abscess, furuncle and carbuncle & 15 & 1.4 & 77 & 0.7 & 1.95 & $1.13-3.35$ \\
\hline A09 & $\begin{array}{l}\text { Infectious gastroenteritis and colitis, } \\
\text { unspecified }\end{array}$ & 29 & 2.7 & 164 & 1.5 & 1.77 & $1.20-2.60$ \\
\hline J06 & $\begin{array}{l}\text { Acute upper respiratory infections of } \\
\text { multiple and unspecified sites }\end{array}$ & 41 & 3.8 & 237 & 2.2 & 1.73 & $1.25-2.39$ \\
\hline
\end{tabular}




\begin{tabular}{|c|c|c|c|c|c|c|c|}
\hline ICD code & Disease & MS & $\%$ & Controls & $\%$ & OR & $95 \% \mathrm{CI}$ \\
\hline I06 & Rheumatic aortic valve diseases & 1 & 0.09 & 6 & 0.06 & 1.67 & $0.21-13.52$ \\
\hline $\mathrm{I} 10$ & Essential (primary) hypertension & 93 & 8.66 & 1034 & 9.63 & 0.90 & $0.74-1.10$ \\
\hline I11 & Hypertensive heart disease & 2 & 0.19 & 35 & 0.33 & 0.57 & $0.14-2.33$ \\
\hline $\mathrm{I} 12$ & Hypertensive chronic kidney disease & 1 & 0.09 & 3 & 0.03 & 3.33 & $0.40-28.10$ \\
\hline $\mathrm{I} 15$ & Secondary hypertension & 7 & 0.65 & 23 & 0.21 & 3.04 & $1.36-6.79$ \\
\hline $\mathrm{I} 20$ & Angina pectoris & 12 & 1.12 & 141 & 1.31 & 0.85 & $0.47-1.53$ \\
\hline $\mathrm{I} 21$ & Acute myocardial infarction & 18 & 1.68 & 121 & 1.13 & 1.49 & $0.91-2.43$ \\
\hline $\mathrm{I} 22$ & Subsequent myocardial infarction & 2 & 0.19 & 2 & 0.02 & 10.00 & $2.05-48.82$ \\
\hline $\mathrm{I} 23$ & $\begin{array}{l}\text { Certain current complications following } \\
\text { myocardial infarction }\end{array}$ & 1 & 0.09 & 2 & 0.02 & 5.00 & $0.58-43.34$ \\
\hline $\mathrm{I} 25$ & Chronic ischemic heart disease & 25 & 2.33 & 259 & 2.41 & 0.97 & $0.64-1.45$ \\
\hline $\mathrm{I} 26$ & Pulmonary embolism & 11 & 1.02 & 52 & 0.48 & 2.12 & $1.12-3.99$ \\
\hline $\mathrm{I} 33$ & Acute and subacute endocarditis & 1 & 0.09 & 4 & 0.04 & 2.50 & $0.30-20.75$ \\
\hline $\mathrm{I} 34$ & Nonrheumatic mitral valve disorders & 5 & 0.47 & 63 & 0.59 & 0.79 & $0.32-1.96$ \\
\hline $\mathrm{I} 35$ & Nonrheumatic aortic valve disorders & 4 & 0.37 & 65 & 0.61 & 0.62 & $0.23-1.67$ \\
\hline I36 & Nonrheumatic tricuspid valve disorders & 1 & 0.09 & 4 & 0.04 & 2.50 & $0.30-20.75$ \\
\hline $\mathrm{I} 40$ & Acute myocarditis & 1 & 0.09 & 6 & 0.06 & 1.67 & $0.21-13.52$ \\
\hline $\mathrm{I} 42$ & Dilated cardiomyopathy & 2 & 0.19 & 26 & 0.24 & 0.77 & $0.18-3.22$ \\
\hline I44 & $\begin{array}{l}\text { Atrioventricular and left bundle-branch } \\
\text { block }\end{array}$ & 6 & 0.56 & 42 & 0.39 & 1.43 & $0.61-3.34$ \\
\hline $\mathrm{I} 45$ & Other conduction disorders & 6 & 0.56 & 41 & 0.38 & 1.46 & $0.63-3.42$ \\
\hline I46 & Cardiac arrest & 1 & 0.09 & 4 & 0.04 & 2.50 & $0.30-20.75$ \\
\hline I47 & Paroxysmal tachycardia & 9 & 0.84 & 84 & 0.78 & 1.07 & $0.54-2.12$ \\
\hline $\mathrm{I} 48$ & Atrial fibrillation and flutter & 18 & 1.68 & 350 & 3.26 & 0.51 & $0.33-0.81$ \\
\hline I49 & Other cardiac arrhythmias & 18 & 1.68 & 189 & 1.76 & 0.95 & $0.59-1.54$ \\
\hline $\mathrm{I} 50$ & Heart failure & 19 & 1.77 & 124 & 1.15 & 1.53 & $0.95-2.47$ \\
\hline $\mathrm{I} 60$ & Nontraumatic subarachnoid hemorrhage & 5 & 0.47 & 24 & 0.22 & 2.08 & $0.81-5.34$ \\
\hline I61 & Nontraumatic intracerebral hemorrhage & 4 & 0.37 & 26 & 0.24 & 1.54 & $0.54-4.37$ \\
\hline I63 & Cerebral infarction & 25 & 2.33 & 161 & 1.50 & 1.55 & $1.03-2.35$ \\
\hline I67 & Other cerebrovascular diseases & 9 & 0.84 & 36 & 0.34 & 2.50 & $1.24-5.06$ \\
\hline I69 & Sequelae of cerebrovascular disease & 18 & 1.68 & 104 & 0.97 & 1.73 & $1.06-2.83$ \\
\hline $\mathrm{I} 70$ & Atherosclerosis & 12 & 1.12 & 102 & 0.95 & 1.18 & $0.65-2.13$ \\
\hline I71 & Aortic aneurysm and dissection & 3 & 0.28 & 26 & 0.24 & 1.15 & $0.35-3.80$ \\
\hline
\end{tabular}

Additional table. The number, percentage and coincident odds ratio (OR) with 95\% confidence interval (CI) for the ICD-10 circulatory disease diagnoses I06-I71 for the MS and age- and gender matched control cases from 1.1.2004 to to 31.12.2012 in the Hospital Distict of Southwest Finland. 